\title{
Effects of Intervention Programs on Child and Adolescent BMI: A Meta-Analysis Study
}

\author{
Catarina Vasques, Pedro Magalhães, António Cortinhas, Paula Mota, \\ José Leitão, and Vitor Pires Lopes
}

\begin{abstract}
Background: This meta-analysis study aims to assess the efficacy of school-based and after-school intervention programs on the BMIs of child and adolescents, addressing the correlation between some moderating variables. Methods: We analyzed 52 studies $(\mathrm{N}=28,236)$ published between 2000-2011. Results: The overall effect size was $0.068(P<.001)$, school $(r=.069)$ and after-school intervention $(r=.065)$. Programs conducted with children aged between $15-19$ years were the most effective $(r=.133)$. Interventions programs with boys and girls show better effect sizes $(r=.110)$ than programs that included just girls $(r=.073)$. There were no significant differences between the programs implemented in school and after-school $(P=.770)$. The effect size was higher in interventions lasting 1 year $(r=.095)$, with physical activity and nutritional education $(r=$ .148), and that included 3-5 sessions of physical activity per week $(r=.080)$. The effect size also increased as the level of parental involvement increased. Conclusions: Although of low magnitude $(r=.068)$, the intervention programs had a positive effect in prevention and decreasing obesity in children. This effect seems to be higher in older children's, involving interventions with physical activity and nutritional education combined, with parent's participation and with 1-year duration. School or after-school interventions had a similar effect.
\end{abstract}

Keywords: obesity, effect-size, school, after-school

The International Obesity Task Force recently reported that approximately 155 million school-aged children are overweight or obese worldwide. ${ }^{1}$ Sedentary habits such as screen viewing as well as excessive energy intake have been associated with a high risk of developing childhood obesity. 2,3 These styles of behavior have been frequently associated with low levels of physical activity (PA) and obesity, ${ }^{4}$ which may increase the risk of several organic disorders, such has hypertension, ${ }^{5-7}$ type 2 diabetes, ${ }^{8}$ osteoporosis, ${ }^{9-11}$ hypercholesterolemia, and insulin resistance. ${ }^{12}$

Several medical and scientific institutions (American Heart Association, Center for Disease Control USA, American College of Sports Medicine, National Institutes of Health) have demonstrated their great concern with decreased levels of PA in children and young people, declaring the adoption of an active lifestyle at this age to be of paramount importance. Understanding the factors that allow intervention programs to succeed in reducing obesity is one of the most important challenges among epidemiologists and public health researchers.

\footnotetext{
Vasques, Magalhães, and Lopes are with the Sports Science Dept, Research Center in Sports Sciences, Health Sciences, and Human Development (CIDESD), Polytechnic Institute of Bragança, Portugal. Cortinhas, Mota, and Leitão are with the Sport, Exercise, and Health Dept, University of Trás-os-Montes and Alto Douro, Vila Real, Portugal.
}

Since childhood and youth are seen as the age periods in which PA habits are acquired and consolidated, it is of extremely important to implement PA intervention programs for young people. This type of intervention should effectively encourage children as well as their family and friends to adopt an active lifestyle.

Many intervention programs have been developed based on design priorities such as a) increasing levels of PA and education about healthy eating, ${ }^{13-15} \mathrm{~b}$ ) decreasing the sedentary behaviors, ${ }^{16,17} \mathrm{c}$ ) increasing welfare of children by improving their body image and self-esteem, ${ }^{18}$ as well as d) discouraging the consumption of soft drinks, promoting the consumption of water, and emphasizing the importance of balance in quality of life. ${ }^{19}$

Some review studies have demonstrated the heterogeneity of obesity prevention programs for children. Previous meta-analysis studies have focused on the effect size of intervention programs conducted either exclusively in school $^{20-24}$ or exclusively after-school. ${ }^{25}$ However, there have been no meta-analysis studies that systematically review the effect of both types of intervention programs (ie, in school and after-school) on body composition (measured by BMI) in children and adolescents.

The purpose of this study is to assess the efficacy of the school-based and after school interventions programs on children and adolescents BMI reduction considering the correlation between some moderating variables, and intend to be an update of the effect size estimate of intervention programs on children BMI. 


\section{Methods and Procedures}

This meta-analysis was conducted in accordance with the recommendations and criteria outlined in the Preferred Reporting Items for Systematic Reviews and MetaAnalysis statement. ${ }^{26}$

With the purpose to update the information related with the effect size estimation of intervention programs on children's body composition, only articles published between 2000-2011 were included. Worldwide children's obesity and overweight have been rising in the last years, which have increased concerns and publications on this subject. Part of these publications relied on descriptive studies on children's obesity incidence and only more recently research have concerned on implementing strategies to face this problem. So, this meta-analysis focuses on the effectiveness of the last years implementing programs to face children's obesity.

\section{Data Sources and Search Strategy}

The following databases were searched for articles published between 2000-2011: PubMed MEDLINE; Web of science (Web of ScienceSM; Current Contents Connect); List at EBSCO (Academic Search Complete); Latindex; SciELO.org and editors: Elsevier, Wiley, Springer, Taylor $\&$ Francis. The keywords used for searching were "physical activity interventions" or "prevention programs" and "school-based" or "after-school" and "obesity" or "overweight" and "child" or "adolescent" and "BMI" or "body composition" or "body fat." The references of all retrieved studies were examined to detect other potential relevant studies not identified by the database searches.

\section{Inclusion Criteria}

School and after-school intervention programs with children under 19 years old that used randomized controlled trials or nonrandomized clinical trials with a group that was not submitted to any intervention (control group) were included. Only studies that applied intervention programs for at least 6 weeks and reported the effect size on children's body mass index (BMI) were considered. Studies were also included that indicated the effect size of intervention or the pre- and postintervention values of BMI, BMI $z$ score, BMI d score, BMI percentile, percentile of overweight/obesity, or body fat.

The selected studies applied interventions programs that aimed to a) increase the levels of PA by adapting the school curriculum and providing an effective increase in time spent in PA and sports practices (playing ball, running, jumping, dancing, volleyball, soccer, handball, swimming, aerobic exercise and other), both at school and during leisure time; b) change and control the diet of children in schools or at home by reducing intake of hyper-caloric foods and drinks and promoting increased intake of vegetables and other foods low in calories; and c) reduce sedentary activities, such as watching television or playing video games, offering follow-up sessions about healthy behaviors.

\section{Selection of Moderator Variables}

Moderator variables largely based on the models presented by Cook-Cottone et $\mathrm{al}^{23}$ and Stice et $\mathrm{al}^{27}$ were chosen. Two authors of the current study were responsible for separately encoding each of the moderator variables, which were then compared with ascertain the percentage of agreement. The description of the criteria for coding is presented in the following section.

\section{Moderator Variables and Coding Criteria}

The variables included as moderator were previously specified and all presented, independently of their level of significance

Age. According to the recommendations established by the American Academy of Pediatrics,${ }^{28}$ the prevention of obesity is a relevant concern for children of all ages. Thus, the current review will take into account the average age of children as a potential moderator. Using the mean age of each study, children 10 years of age or younger were classified as "Elementary," children who were at least 10 years of age but not older than 15 were coded as "Middle school age," and children over 15 and younger than 19 were coded as "High school age." When the ages of the participants overlapped 2 of these intervals, combined coding was used: "Elementary/ Middle school age" or "Middle school age/High school age."

Sex. Since some authors ${ }^{29,30}$ have found different effects of intervention programs, depending on the sex of the children, it is appropriate to examine sex as a moderator variable. In this study, the gender of the participants included the following groups: a) girls only, b) mixed (girls and boys), and c) mixed groups where girls and boys were analyzed separately. A group with boys only was not included in the present analysis because no intervention programs exclusively with boys were found in the literature.

In School or After-School. Several studies indicated that both intervention programs in school ${ }^{31,32}$ and afterschool $^{33,34}$ have a positive effect in prevention and in decreasing the obesity in children. In this case, the effect size of intervention programs in school varied between $r=.36$ and $r=.39$ and in after-school intervention programs varied between $r=.23$ and $r=.58$. However, the effectiveness of both types of intervention is unknown. To analyze the effect size of programs conducted in schools compared with interventions outside the school, we consider this variable as a potential moderator.

Intervention programs conducted within school were coded with "School," and those that occurred outside school were coded "After-school."

Type of Intervention. Since obesity is a multifactorial problem, intervention programs normally involve a combination of several variables, such as nutritional education, PA, and reduction of sedentary behaviors, frequently involving family members in these efforts. To examine the effect of each of these variables separately or in combination we considered them as potential moderator variables. 
The type of intervention program under analytical review was cataloged as physical activity (PA), nutrition (D), or change in lifestyle (LS). When appropriate, programs combining the aforementioned variables were also included.

Duration of Intervention. Some authors ${ }^{23}$ have shown that interventions of moderate to long terms are associated with a greater effectiveness in reducing BMI.

On the other hand, Vanhelst et $\mathrm{al}^{35}$ reported that shortterm programs are most effective. Therefore, the duration of programs was considered as a moderator variable.

The duration of the intervention programs were coded as: " $<1$ " if the duration was between 6 weeks and 12 months, "1 year" when the duration was between 10 and 12 months (academic year and calendar year), or " $>1$ " if the duration was more than 1 year.

Physical Activity Frequency. Several authors ${ }^{36,37}$ have determined that low levels of PA in children and young people increase the risk of developing obesity. Nonetheless, no consensus has been reached regarding the ideal number of PA sessions needed to achieve an optimal effect. Thus, we considered the frequency of PA as a moderator variable. We code the frequency of intervention as: minimal (1-2 times per week), moderate (3-5 times per week), or high (more than 5 times per week). The intensity of PA was not considered because it is not described in most of the studies.

Parental Involvement. Family involvement is considered important in ensuring changes in nutrition and PA levels of children, since parents usually control their children's food choices and leisure-time practices PA. ${ }^{22}$ However, the review carried out by Cook-Cottone et $\mathrm{al}^{23}$ showed nonsignificant differences in the effects of programs that included parents compared with those that did not include them. To try to establish the effect of parental involvement on the prevention of obesity in children, we coded this variable as a potential moderator.

Parental involvement was coded as a) minimal parental involvement, b) moderate parental involvement, c) high parental involvement, or d) no parental involvement.

\section{Outcome Measurement}

Excess of weight is commonly identified by calculating the body mass index (BMI), by quantifying the body composition, or by measuring waist perimeter or skinfolds of subcutaneous fat. According to the classification proposed by Cole et al, ${ }^{38}$ all subjects between $2-18$ years were categorized in a standardized manner using the same criteria (normal weight, overweight, or obese). BMI z scores and BMI were selected as outcome measures because they have shown a high correlation with adiposity values. ${ }^{39}$ In addition, these measures are the most commonly used in studies evaluating the effects of intervention on the prevention of obesity in children. ${ }^{38,39}$

However, some authors ${ }^{40}$ have suggested that changes associated with physical growth as well as the individual variability inherent to puberty make the results of BMI by age difficult to interpret. For this reason, the use of classifications of sexual maturation is recommended to control for differences between preadolescent children and adolescents. ${ }^{40}$

\section{Statistical Analysis}

This meta-analysis included 19 articles where the correlation value $(r)$ between the variables in question was present and was taken directly as the effect size value. In other studies, the value of $r$ (effect size) was calculated using the mean values and standard deviations of the initial and final 2 groups (treatment and control). According to Cohen the effect sizes to test the significance of product moment correlation coefficient $(r)$ are, .10, .30, and .50, for small, medium, and large, respectively. ${ }^{41}$

Analyses were computed using subgroups that were determined using moderator variables, and the $\mathrm{Q}_{\mathrm{B}}$ test was used to determine the influence of each variable.

Fixed-effect analyses were conducted, and study weights (ie, how much a study is factored into an overall effect estimate) are proportional to sample size and standard error.

To test for evidence of publication bias, we examined a standard funnel plot. ${ }^{42}$ In addition to this graphical check for bias, we also used the rank-correlation test of Begg and Mazumdar, ${ }^{43}$ which is a formal statistical test of bias that are based on the same consideration that underlies the funnel plot.

The heterogeneity of the studies was evaluated by their statistical values for $\mathrm{Q}$ and $\mathrm{I}^{\wedge} 2 .^{44}$

Statistical analysis was performed using Comprehensive Meta-Analysis (CMA) version 2.2.048. ${ }^{45}$

\section{Results}

\section{Study Selection}

An initial search using the keywords described located 778 studies. After reading titles and abstracts, the number of studies was reduced to 188 . Of these, 83 were experimental studies of intervention programs for children and adolescents; the others were archived since they only referenced desirable content such as determinants of obesity in children (42 studies), meta-analysis and systematic review (17 studies), prevalence of obesity in children (44 studies), or habitual physical activity (4 studies), among others.

After reading the abstracts and in some cases the full text, the number was reduced to 67 studies.

In the final refinement of the research, once the criteria for the inclusion of studies had been defined, only 52 studies fulfilled all necessary requirements.

\section{Excluded Studies}

Studies of the intervention programs that did not have a control group (1), or intervened only in subjects' diets (1), were excluded. Studies (4) involving children suffering from eating disorders or drug or alcohol problems were not used. 
Trials that were only descriptive (6) were also excluded.

\section{Studies Characteristics}

Seventeen of the programs were carried out after school, while the remaining 35 occurred in school settings. Of the 52 studies included, only 11 intervention programs were exclusively based on PA. Ten intervention programs combined PA and D. Eleven intervention programs aimed at lifestyle changes (LS) by controlling variables such as interactive multimedia, nutrition education, nutrition policy, social marketing, encouragement of physical activity, and health related sessions.

There were included 9 studies involving PA and LS interventions, and 4 studies with D and LS.

Programs that combined all 3 components (PA, D, and LS) represented the remaining 7 studies.

In terms of program duration, 7 studies took place over the course of 1 year, 33 programs lasted less than 1 year, and the remaining 12 were longer than 1 year.

The intervention of the parents was requested in 26 programs; the remaining 25 studies involved only children. In 1 study, the 2 possibilities were both studied.

\section{Participant Characteristics}

The analysis included a total of 28,236 children and adolescents. In 28 of the analyzed studies, the participants were 10 years of age or younger, in 14 studies the participants were over 10 years old but not older than 15 , and in 4 of them the subjects' ages were over 15 but less than 19. Age groups of 5-12 years were included in 6 studies, and a sample between 12-19 years of age was considered in 1 study. One study examined separate samples that contained one group of third graders and another group of fourth to seventh graders.

In most of the studies the samples comprised children of both genders ( 37 studies), while 7 of the studies had only girls. In 8 studies, boys and girls were analyzed separately.

\section{Analysis of Studies}

The synthesis of the studies included in the analysis is presented in Table 1. It shows a summary of the methodology used in each of the programs implemented in school or after school to prevent or combat obesity in children and adolescents. The number of subjects and the length of intervention is also described, as well as the evaluated outcome measurement.

The weighted mean difference in change in BMI, BMI $z$ score, percentile BMI, and overweight/obesity between the intervention group and the control group can be seen in Figure 1. The size of each data marker indicates the weight assigned to the individual study.

\section{Effect Analysis of Moderators}

The results indicated a significant effect in 52 studies $(\mathrm{N}$ $=28,236) r=.068, P=.000(95 \%$ confidence interval
$=0.058,0.079)$. Although this effect is of low magnitude $^{41}$ the results from the 2 different tests showed no bias' evidence of publications. The funnel plot shows a symmetrical distribution of points, reminding 1 inverted funnel, and the rank-correlation test of Begg and Mazum$\operatorname{dar}^{43}(P=.42)$ confirm this lack of bias (see Figure 2).

A test for heterogeneity of variance indicates that the results of the study are significantly higher than would be expected, Q (72) = 708.046, $P=.000$. This indicates that there are studies or moderator variables that explain the variation in effect size.

Table 2 shows the effect sizes of each moderator variable on BMI.

Regarding the characteristics of the participants, it can be seen that the age is a moderator of effect size, showing a statistically significant difference between groups $(P<.001)$. Interventions targeting elementary $(r=.106)$ and high school aged $(r=.133)$ participants had a higher effect size. Programs that intervened with children between 10 and 15 years old, despite being statistically significant $(P=.001)$, demonstrated a smaller effect size $(r=.027)$. There was no significant effect in the intervention group aged between 10 and 19 years $(P=$ $.391)$, although the size of its effect is positive $(r=.041)$.

Intervention programs with boys and girls show the highest effect size (data from boys and girls pooled together: $r=.110, P<.001)$. Nonetheless, other studies that applied the same intervention program to girls and boys but presented results separately for each gender revealed that the effect size was higher in the girls $(r$ $=.030, P<.005)$ than in the boys $(r=.005, P=.642)$. When the intervention programs were done exclusively with girls, the effect size was higher $(r=.073, P=.015)$.

The results show that intervention programs at school had a higher effect $(r=.069)$ than the programs in after-school settings $(r=.065)$, however the effect is not significantly different $(P=.770)$.

When the intervention had a duration of less than 1 year, the effect size was lower $(r=.046, P=.000)$ than those that lasted 1 year $(r=.095, P=.000)$ or more $(r$ $=.086, P=.000)$. In all of these cases, the effect size between the duration of intervention was statistically significant $(P=.001)$.

A statistically significant effect $(P<.005)$ was found in all types of interventions considered in the present analysis $(\mathrm{PA}, \mathrm{LS}, \mathrm{PA}+\mathrm{D}, \mathrm{D}+\mathrm{LS}$, and $\mathrm{PA}+\mathrm{D}+\mathrm{LS})$, with the exception of the PA+LS programs $(P=.060)$.

The programs that focused on children's PA and D were the most successful, with an effect size of 0.148 . Positive effects were also obtained by interventions only in LS $(r=.088)$, and in LS combined with $\mathrm{D}(r=.082)$. When the intervention concentrated only on increasing the PA levels of children and young people, the effect size was smaller $(r=.029) P=.027$.

In the 11 programs that combined AF, $\mathrm{LS}$, and $\mathrm{D}$ in the form of intervention, although the results obtained were statistically significant $(P<.001)$, the effect size was only 0.047 .

The effect of the programs involving PA sessions was statistically significant when the frequency of the 


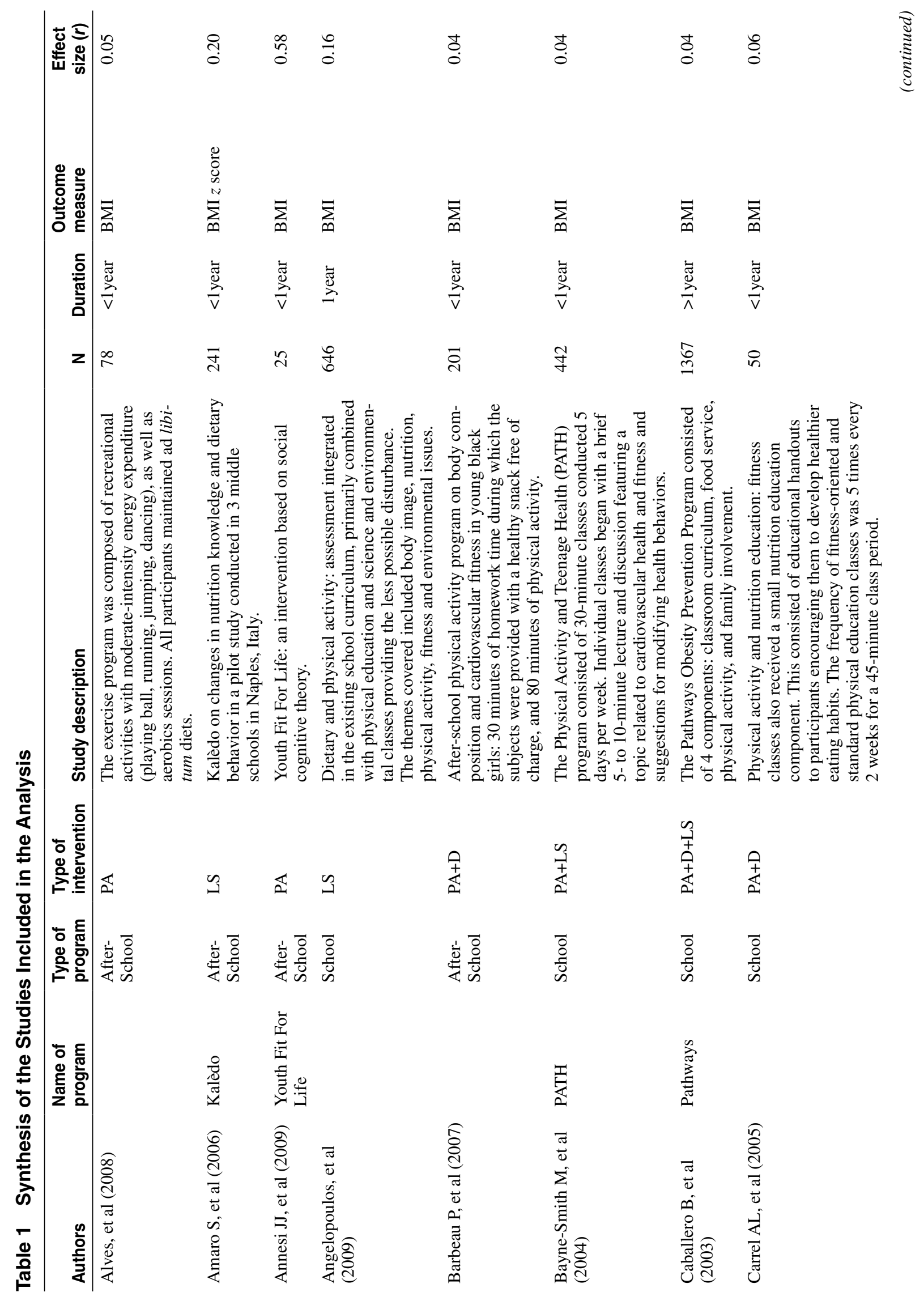




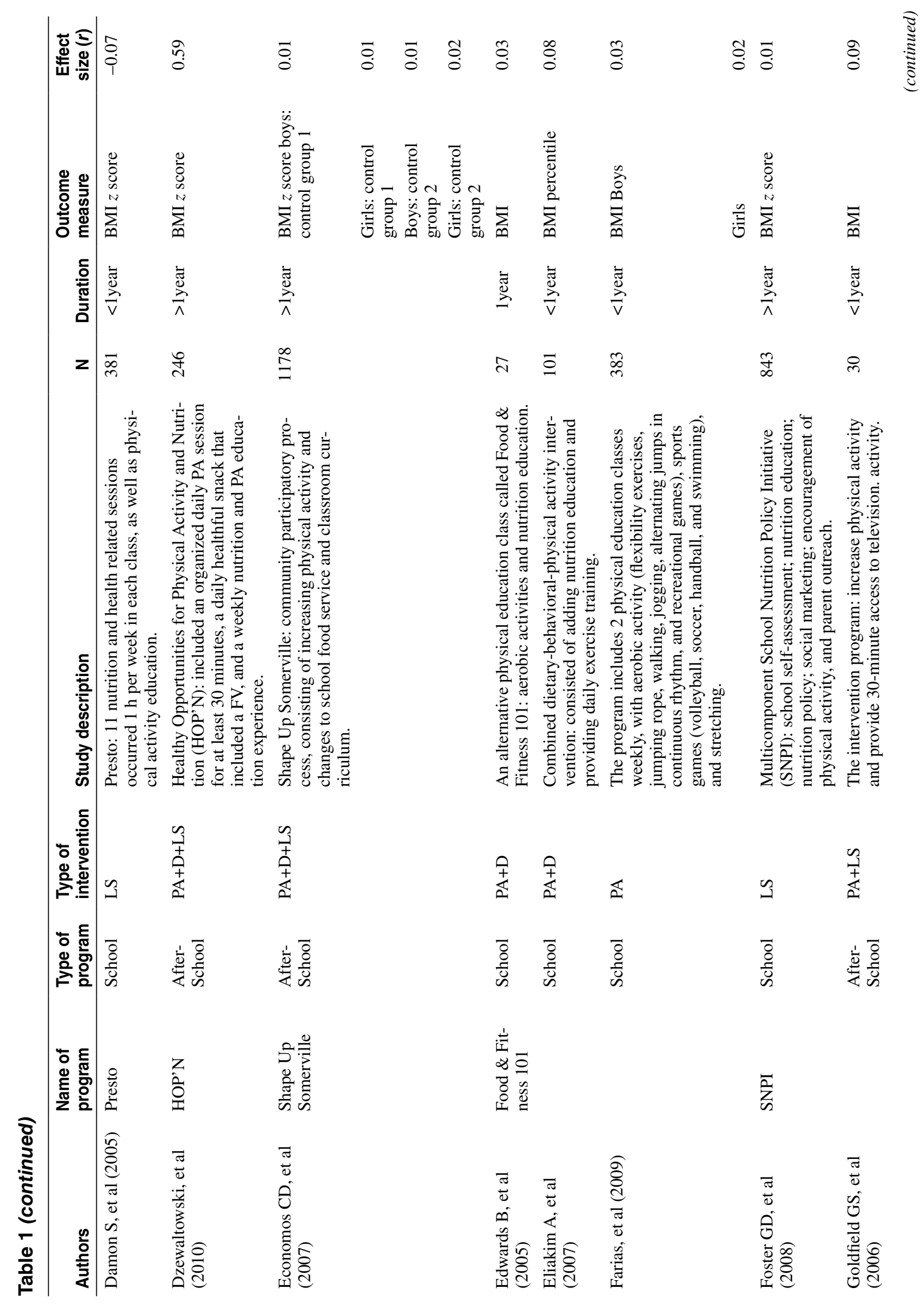




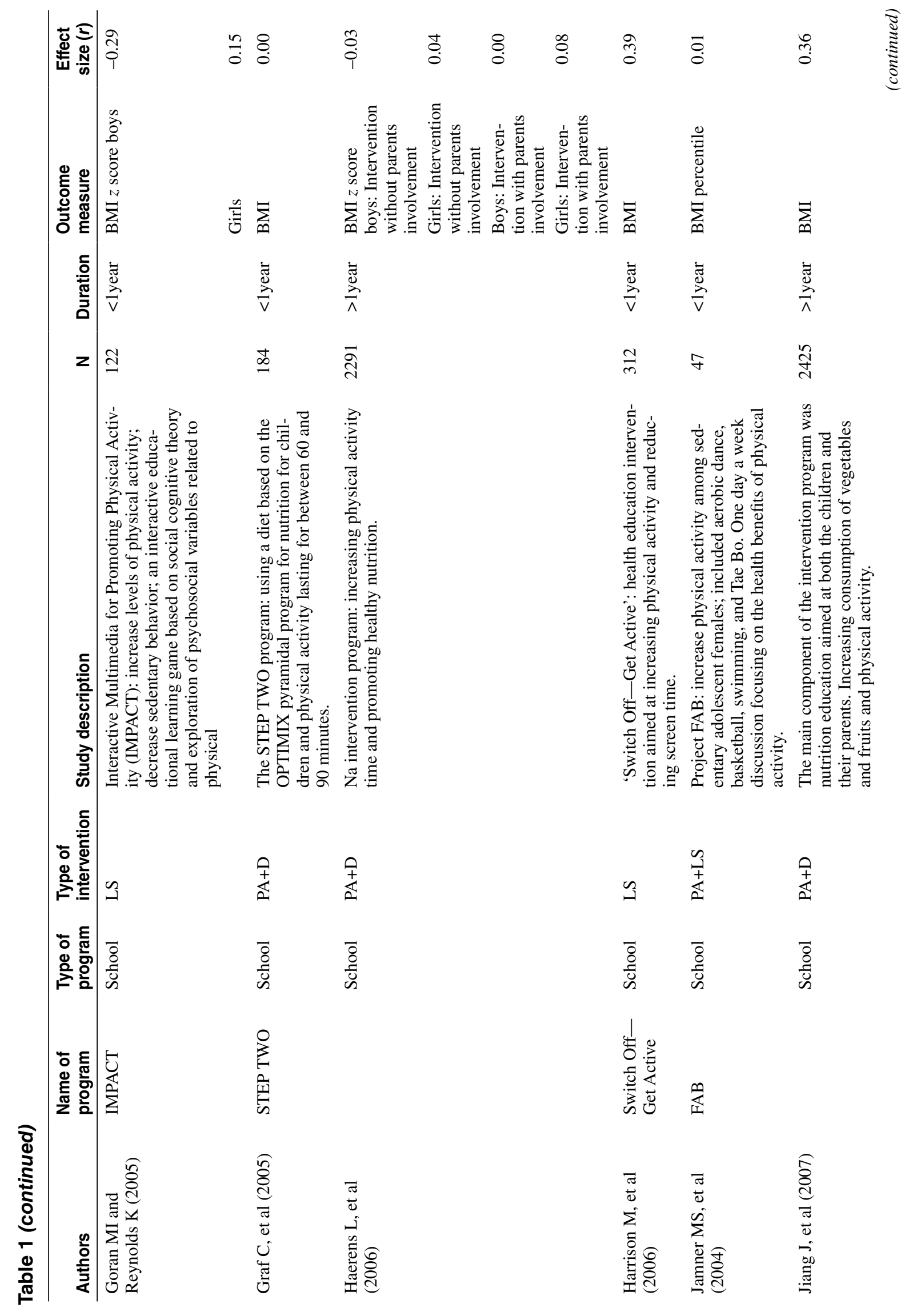




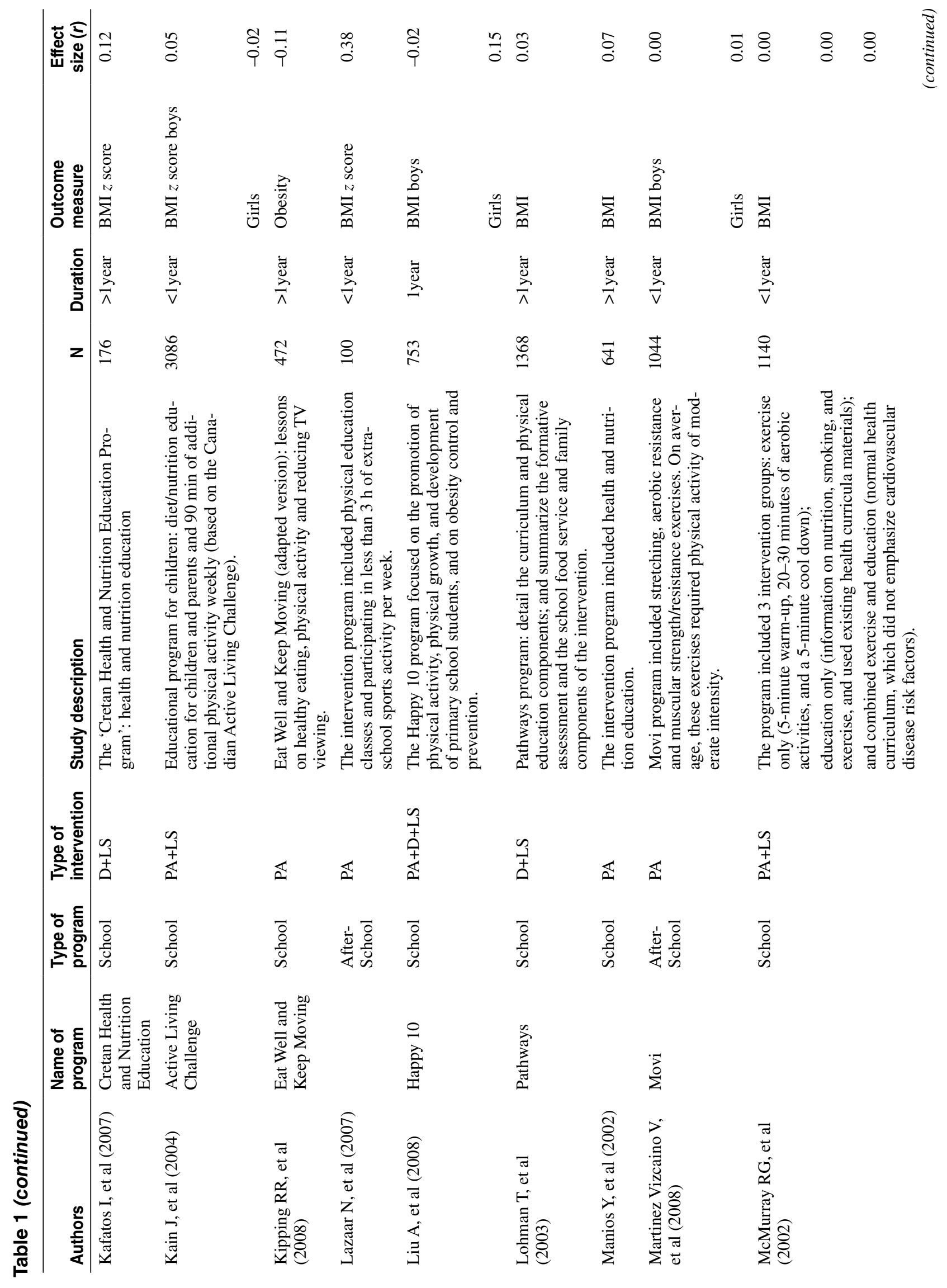




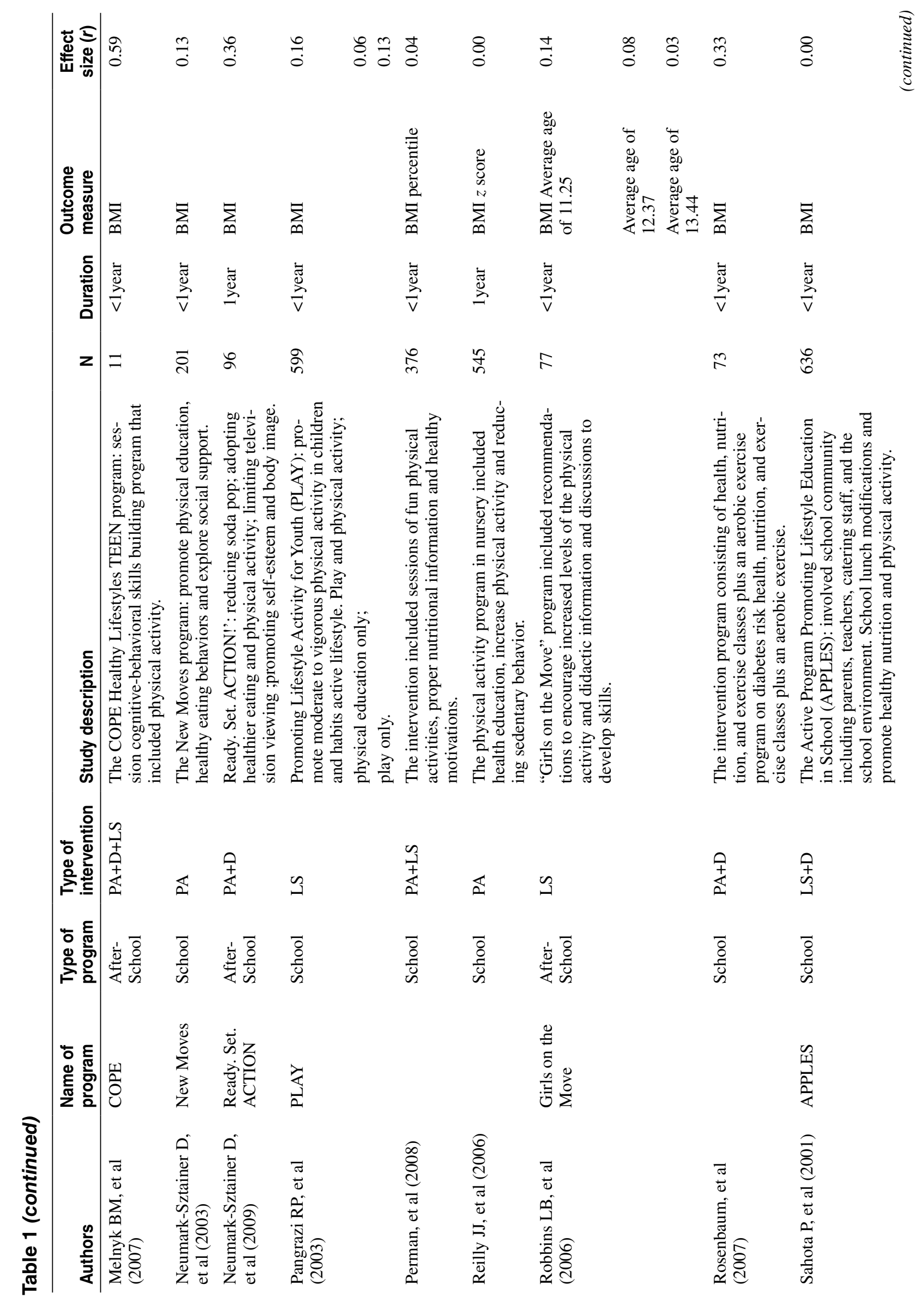




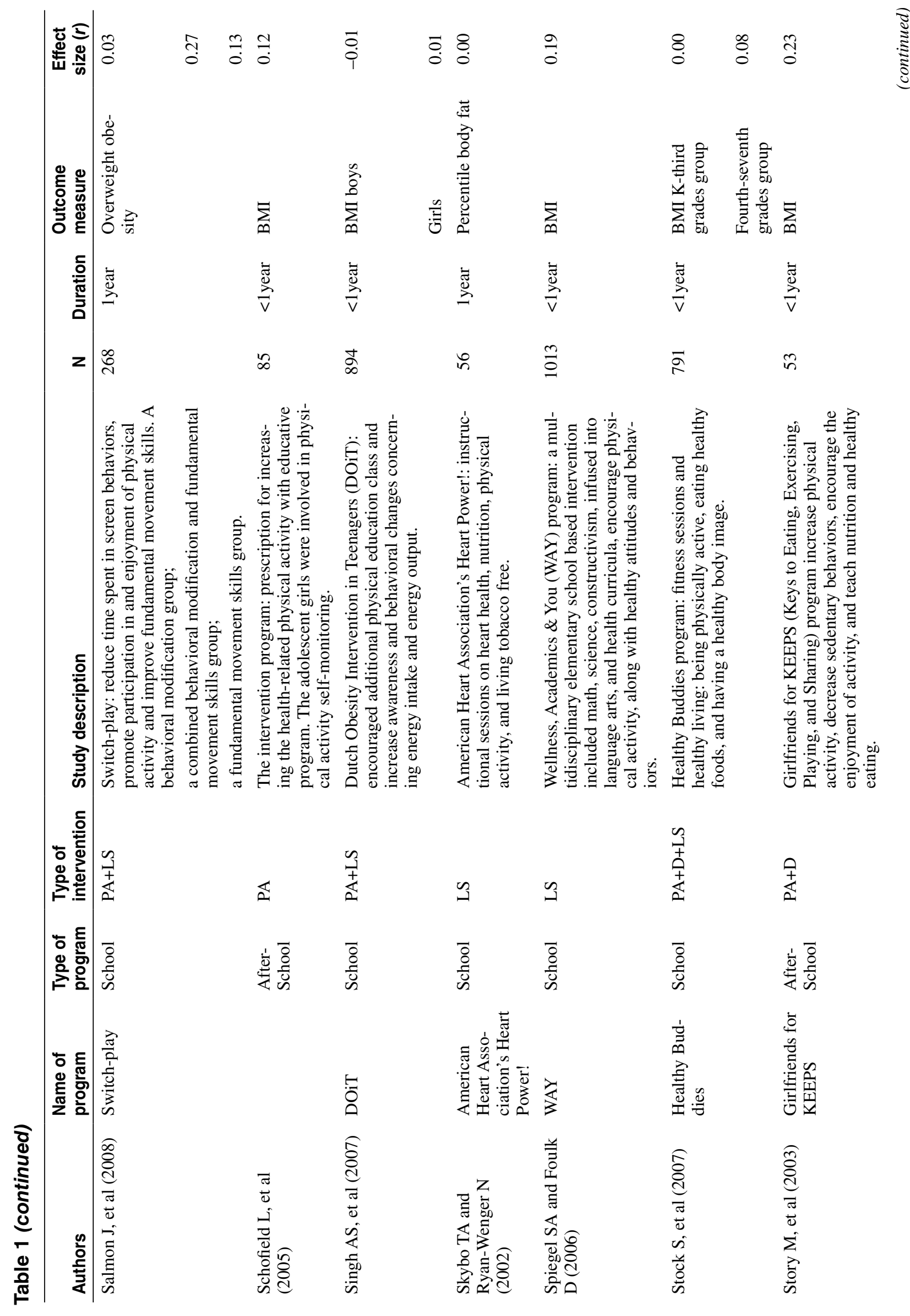




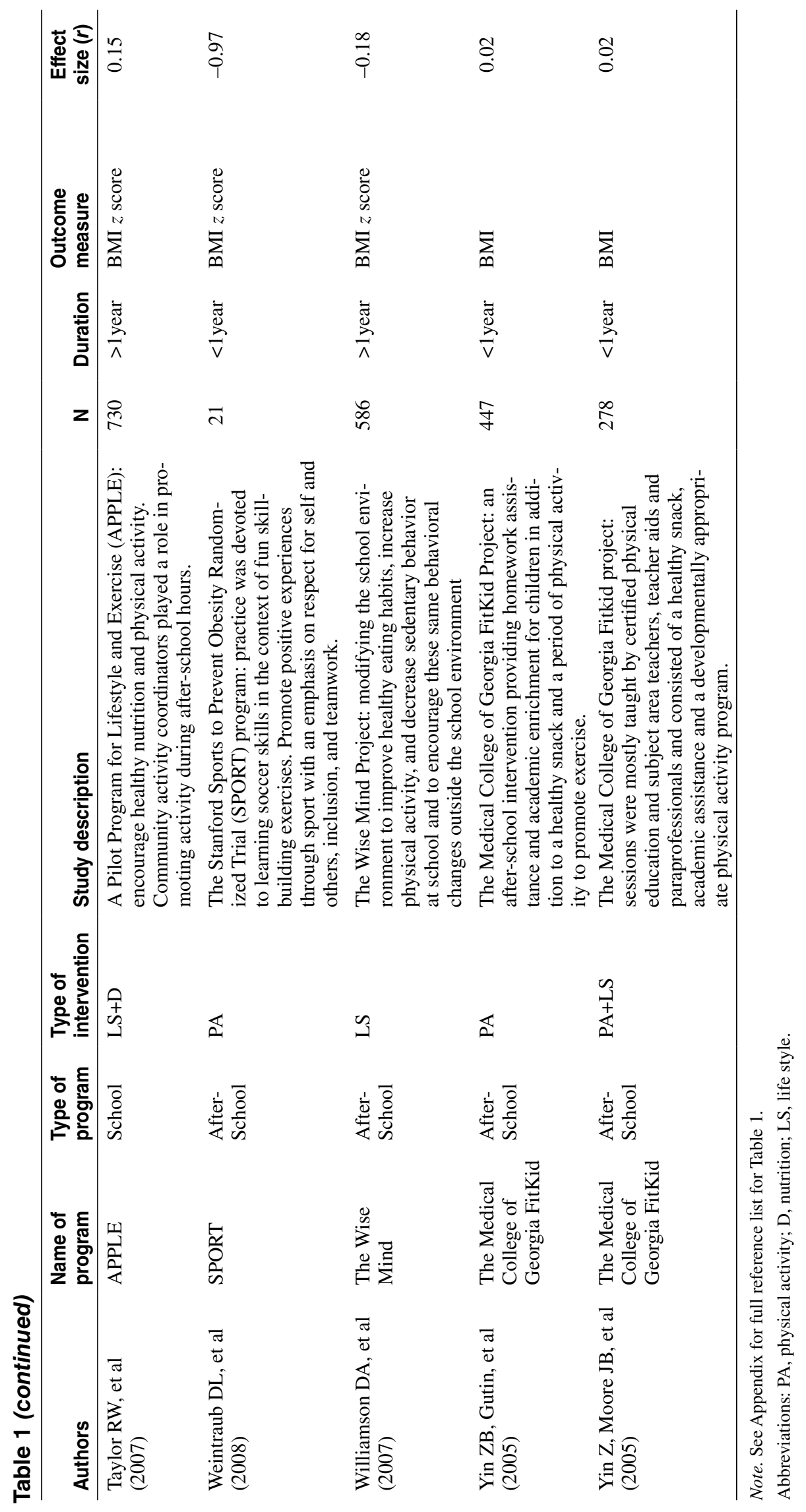




\section{Study}

Alves et al. (2008)

Amaro, S. et al (2006)

Angelopoulos et al (2009)

Annesi J. J et al (2009)

Barbeau. P. et al. (2007)

Bayne-Smith. M. et al. (2004)

Caballero, B. et al (2003)

Carrel, A. L et al. (2005)

Damon, S. et al. (2005)

Dzewaltowski et al. (2010)

Economos, C. D. et al. (2007) a

Economos, C. D. et al. (2007) b

Economos, C. D. et al $(2007)$ c

Economos, C. D. et al (2007) d

Edwards, B. et al. (2005)

Eliakim, A. et al (2007)

Farias et al. (2009)

Farias et al. (2009) b

Foster, G. D. et al. (2008)

Goldfield G. S, et al (2006)

Goran, M. I. and K. Reynolds (2005) a

Goran, M. I. and K. Reynolds (2005) b

Graf, C. et al. (2005)

Haerens, L et al. (2006) b

Haerens, L et al. (2006) c

Haerens, L et al. (2006) d

Haerens. L et al. (2006)a

Harrison, M. et al. (2006)

Jamner, M. S. et al. (2004)

Jiang. J., X. Xia, et al. (2007)

Kafatos, I. et al. (2007)

Kain, J. et al. (2004)

Kain, J. et al. (2004) b

Kipping. R. R. et al. (2008)

Lazaar, N. et al (2007)

Liu, A., X. Hu, et al. (2008)

Liu, A., X. Hu, et al. (2008) b

Lohman, T. et al. (2003)

Manios, $Y$, et al. $(2002$

Martinez Vizcaino, V. et al (2008)

Martinez Vizcaino, V. et al (2008) b

McMurray, R. G. et al (2002)

McMurray, R. G. et at (2002) b

McMurray, R. G. et al. (2002) c

Melnyk, B. M. et al (2007)

Neumark-Sztainer. D. et al. (2003)

Neumark-Sztainer. D. et al. (2009)

Pangrazi R. P. et al. (2003)

Pangrazi R. P.et al. (2003) b

Pangrazi, R. P.et al. (2003) c

Perman et al. (2008) b

Reilly, J. J.et al (2006)

Robbins, L. B. et al (2006)

Robbins, L. B. et al (2006)b

Robbins, L. B. et al (2006)c

Rosenbaum et al. (2007)

Sahota, P. et al. (2001)

Salmon, J. et al (2008)

Salmon, J. et al. (2008) b

Salmon, J. et al. (2008) c

SChofield, L et al (2005)

Singh, A. S. et al. (2007)

Singh, A. S. et al. (2007) b

Skybo, T. A. and N. Ryan-Wenger (2002

Spiegel, S. A. and D. Foulk (2006)

Stock, S. et al (2007)

Stock, S. et al. (2007) b

Story, M. et al (2003)

Taylor, R. W. et al. (2007)

Weintraub, D. L et al. (2008)

Williamson, D. A. et al $(2007)$

Yin, Z., B. Gutin, et al. (2005)

Yin, Z., J. B. Moore, et al. (2005)
Effect size (r) Cl (95\%)

$\begin{array}{lll}0,050 & -0,170 & 0,266\end{array}$

$\begin{array}{lll}0,200 & 0,076 & 0,318\end{array}$

$0,162 \quad 0,086 \quad 0,235$

$\begin{array}{llll}0.580 & 0.240 & 0.793\end{array}$

$\begin{array}{lll}0.035 & -0.103 & 0.172\end{array}$

$\begin{array}{lll}0.041 & -0.052 & 0.133\end{array}$

$\begin{array}{lll}0,040 & -0,013 & 0,093\end{array}$

$\begin{array}{lll}0,061 & -0,212 & 0,326\end{array}$

$\begin{array}{lll}0,070 & -0,169 & 0,031\end{array}$

$\begin{array}{lll}0,591 & 0,513 & 0,660\end{array}$

$\begin{array}{lll}0,010 & -0,070 & 0,090\end{array}$

$\begin{array}{lll}0.010 & -0,070 & 0.090\end{array}$

$\begin{array}{lll}0,010 & -0,070 & 0,090\end{array}$

$\begin{array}{lll}0.020 & -0,060 & 0.100\end{array}$

$\begin{array}{lll}0,030 & -0,354 & 0,405\end{array}$

$\begin{array}{lll}0,080 & -0,117 & 0,271\end{array}$

$\begin{array}{lll}0.015 & -0,122 & 0.151\end{array}$

$\begin{array}{lll}0.034 & -0.112 & 0.179\end{array}$

$\begin{array}{lll}0,010 & -0,058 & 0.077\end{array}$

$\begin{array}{lll}0.089 & -0.262 & 0.419\end{array}$

$\begin{array}{lll}0,089 & -0,262 & 0,419\end{array}$

$\begin{array}{llll}0,150 & -0,053 & 0,341\end{array}$

$\begin{array}{lll}0,005 & -0,139 & 0,148\end{array}$

$\begin{array}{lll}0,040 & -0,034 & 0,113\end{array}$

$\begin{array}{lll}0.000 & -0.057 & 0.057\end{array}$

$\begin{array}{lll}0,080 & 0,017 & 0,142\end{array}$

$\begin{array}{lll}-0,030 & -0,086 & 0,027\end{array}$

$\begin{array}{lll}0,394 & 0,300 & 0,480\end{array}$

$\begin{array}{lll}0,010 & -0,278 & 0,296\end{array}$

$\begin{array}{lll}0,360 & 0,325 & 0,394\end{array}$

$\begin{array}{lll}0.122 & -0.025 & 0.263\end{array}$

$\begin{array}{lll}0,050 & 0,007 & 0,093\end{array}$

$\begin{array}{lll}-0,020 & -0,064 & 0,025\end{array}$

$\begin{array}{lll}-0,110 & -0,198 & -0,020\end{array}$

$\begin{array}{lll}0,376 & 0,204 & 0,526\end{array}$

$\begin{array}{lll}-0,020 & -0,102 & 0,062\end{array}$

$\begin{array}{lll}0,150 & 0,071 & 0,227\end{array}$

$\begin{array}{lll}0.028 & -0,025 & 0.081\end{array}$

$\begin{array}{lll}0,075 & -0,003 & 0.151\end{array}$

$\begin{array}{lll}0,000 & -0,070 & 0,070\end{array}$

$\begin{array}{lll}0,010 & -0,060 & 0,080\end{array}$

$\begin{array}{lll}0,000 & -0,087 & 0,087\end{array}$

$\begin{array}{lll}0,000 & -0,087 & 0.087\end{array}$

$\begin{array}{lll}0,000 & -0,086 & 0.086\end{array}$

$\begin{array}{lll}0,589 & 0,138 & 0,838\end{array}$

$\begin{array}{lll}0,130 & -0,009 & 0,264\end{array}$

$\begin{array}{lll}0,365 & 0,187 & 0.520\end{array}$

$\begin{array}{lll}0,160 & 0,042 & 0,273\end{array}$

$\begin{array}{lll}0,060 & -0,061 & 0,179\end{array}$

$\begin{array}{lll}0,130 & 0,004 & 0,252\end{array}$

$\begin{array}{lll}0,040 & -0,061 & 0.141\end{array}$

$0,000 \quad-0,084 \quad 0,084$

$\begin{array}{lll}0.138 & -0.214 & 0.458\end{array}$

$\begin{array}{lll}0,077 & -0,253 & 0,391\end{array}$

$\begin{array}{lll}0,029 & -0,474 & 0,517\end{array}$

$\begin{array}{lll}0.325 & 0.113 & 0.508\end{array}$

$\begin{array}{lll}0.000 & -0.078 & 0.078\end{array}$

$\begin{array}{lll}0.030 & -0.154 & 0.212\end{array}$

$\begin{array}{lll}0.270 & 0.094 & 0.430\end{array}$

$\begin{array}{lll}0,130 & -0,041 & 0,294\end{array}$

$\begin{array}{lll}0,118 & -0,098 & 0,323\end{array}$

$\begin{array}{lll}-0,010 & -0,092 & 0,072\end{array}$

$\begin{array}{lll}0,010 & -0,069 & 0,089\end{array}$

$\begin{array}{llll}0.000 & -0.263 & 0.263\end{array}$

$\begin{array}{lll}0,190 & 0,130 & 0,249\end{array}$

$\begin{array}{llll}0,000 & -0,083 & 0,083\end{array}$

$\begin{array}{lll}0,080 & -0,003 & 0,162\end{array}$

$\begin{array}{llll}0.230 & -0,043 & 0.471\end{array}$

$\begin{array}{lll}0.150 & 0.078 & 0.220\end{array}$

$\begin{array}{lll}-0,970 & -0,988 & -0,926\end{array}$

$\begin{array}{lll}-0,180 & -0,257 & -0,100\end{array}$

$\begin{array}{lll}0,020 & -0,073 & 0.113\end{array}$

$\begin{array}{lll}0,020 & -0,098 & 0,137\end{array}$

$\begin{array}{llll}\text { Overall } & 0,068 & 0,058 & 0,079\end{array}$

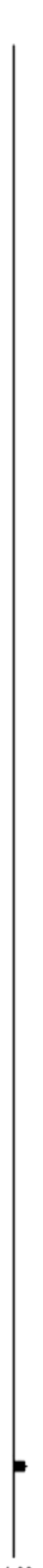

Fav

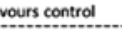

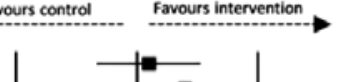

Relative weight

0,23

0,69

0,06

0.58

1,28

3,96
0,15

1,10

0,87

1.74

1.73
1,74

1,73
0,07

0,07

0.59

0.52

2,44
0,09

0,24

0,27

0,53
2,05

3,42

3,42
2,81
3,48

3,48

0,98
0,13

7,03

0.51

6,06

5,62
1,36

0,31

1,66

1,74

3,97
1,87

2,29

2,27

1,48

1,48

1,51

0,04
0,57

0,30

0,30

0,79
0,76

0.69

1,08

1,58

0,09

0,10
0,04

0.22

0.22
1.84
0.32

0,32

0,33

0,38
0,24

1,65

1,65
1,78
0.15

0,15

2,93

1,61
1,61

0.15

0,15

2,11

0,05
1,69

1,29

0.80

Figure 1 - Weighted mean difference in change in body composition between the intervention group and the control group. The size of each data marker indicates the weight assigned to the individual study. These weights are proportional to the inverse of the variance for each study. Larger studies tend to have less variance (because of sample size) and therefore receive more weight. CI $=$ confidence interval. 
Funnel Plot of Standard Error by Fisher's Z

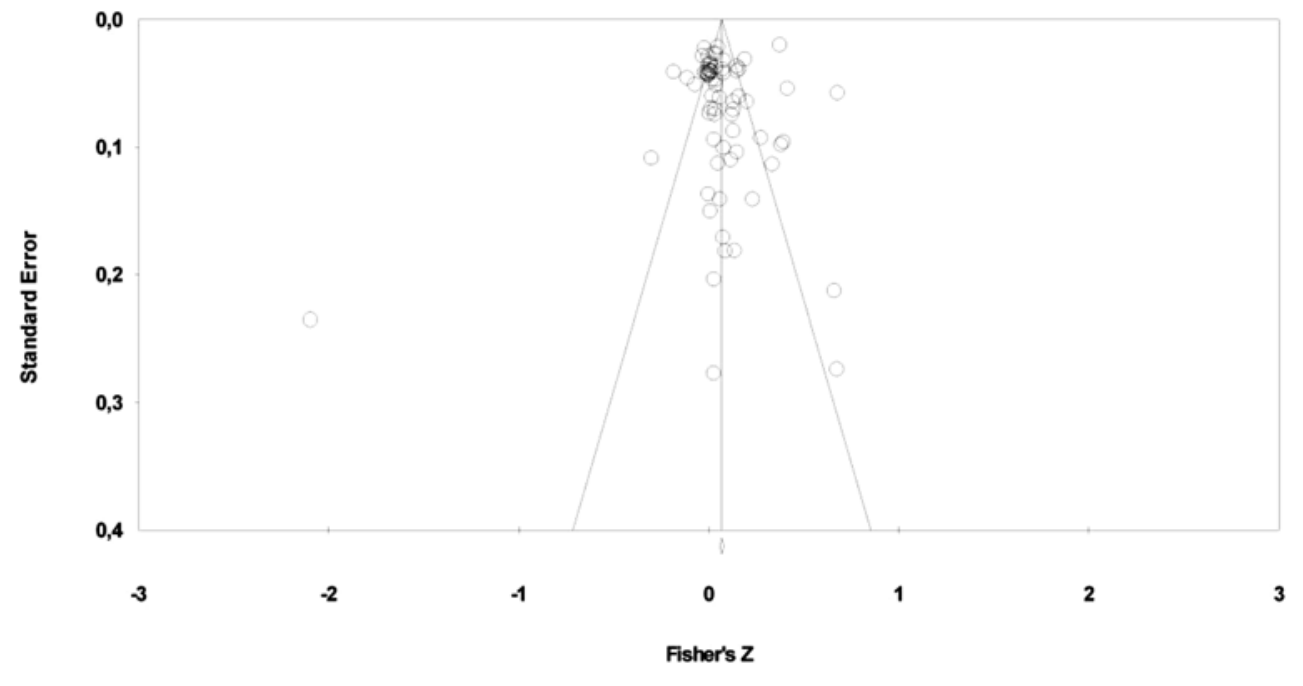

Figure 2 - Funnel plot of studies included in the analysis.

Table 2 Fixed Effects Analysis for Moderators

\begin{tabular}{|c|c|c|c|c|c|c|}
\hline Moderator & Value & K & $r$ & $95 \% \mathrm{Cl}$ & $\boldsymbol{P}$ & $\begin{array}{c}P \text { between } \\
\text { groups }\end{array}$ \\
\hline \multirow[t]{5}{*}{ Age } & Elementary & 36 & 0.106 & $0.091 ; 0.122$ & 0.000 & 0.000 \\
\hline & Elementary/middle school age & 7 & 0.069 & $0.039 ; 0.100$ & 0.000 & \\
\hline & Middle school age & 25 & 0.027 & $0.010 ; 0.043$ & 0.001 & \\
\hline & Middle school age/high school age & 1 & 0.041 & $-0.052 ; 0.133$ & 0.391 & \\
\hline & High school age & 4 & 0.133 & $0.027 ; 0.236$ & 0.014 & \\
\hline \multirow[t]{4}{*}{ Sex } & Males (groups mix) & 10 & 0.005 & $-0.017 ; 0.027$ & 0.642 & 0.000 \\
\hline & Females (groups mix) & 10 & 0.030 & $0.006 ; 0.053$ & 0.013 & \\
\hline & Males+Females & 44 & 0.110 & $0.096 ; 0.124$ & 0.000 & \\
\hline & Females & 9 & 0.073 & $0.014 ; 0.132$ & 0.015 & \\
\hline \multirow[t]{2}{*}{ Type of program } & School & 51 & 0.069 & $0.058 ; 0.081$ & 0.000 & 0.770 \\
\hline & After-school & 22 & 0.065 & $0.040 ; 0.090$ & 0.000 & \\
\hline \multirow{3}{*}{$\begin{array}{l}\text { Duration of } \\
\text { intervention }\end{array}$} & $<$ 1year & 44 & 0.046 & $0.031 ; 0.062$ & 0.000 & 0.001 \\
\hline & 1year & 10 & 0.095 & $0.059 ; 0.131$ & 0.000 & \\
\hline & $>1$ year & 19 & 0.086 & $0.070 ; 0.101$ & 0.000 & \\
\hline \multirow[t]{6}{*}{ Type of intervention } & Physical activity (PA) & 17 & 0.029 & $0.003 ; 0.055$ & 0.027 & 0.000 \\
\hline & Life style (LS) & 16 & 0.088 & $0.061 ; 0.115$ & 0.000 & \\
\hline & Physical activity+Nutrition $(\mathrm{PA}+\mathrm{D})$ & 12 & 0.148 & $0.126 ; 0.171$ & 0.000 & \\
\hline & Physical activity+Life style (PA+LS) & 13 & 0.022 & $-0.001 ; 0.045$ & 0.060 & \\
\hline & Nutrition+Life style (D+LS) & 4 & 0.082 & $0.040 ; 0.124$ & 0.000 & \\
\hline & $\begin{array}{l}\text { Physical activity+Nutrition+Life style } \\
(\mathrm{PA}+\mathrm{D}+\mathrm{LS})\end{array}$ & 11 & 0.047 & $0.023 ; 0.070$ & 0.000 & \\
\hline \multirow{3}{*}{$\begin{array}{l}\text { Physical activity } \\
\text { frequency }\end{array}$} & Minimal & 19 & 0.029 & $0.007 ; 0.050$ & 0.008 & 0.001 \\
\hline & Moderate & 22 & 0.080 & $0.064 ; 0.096$ & 0.000 & \\
\hline & High & 12 & 0.077 & $0.044 ; 0.109$ & 0.000 & \\
\hline \multirow[t]{4}{*}{ Parental involvement } & None & 37 & 0.047 & $0.030 ; 0.064$ & 0.000 & 0.001 \\
\hline & Minimal & 12 & 0.057 & $0.031 ; 0.082$ & 0.000 & \\
\hline & Moderate & 10 & 0.082 & $0.044 ; 0.120$ & 0.000 & \\
\hline & High & 14 & 0.094 & $0.077 ; 0.111$ & 0.000 & \\
\hline
\end{tabular}


interventions were moderate or high $(P<.005)$. However, the 12 programs that occurred 3 to 5 times per week had a greater effect $(r=.080)$ compared with interventions of only 1 to 2 times per week $(r=.029, P=.008)$, or even programs that happened more than 5 times per week $(r$ $=.077)$.

In regard to parental involvement, all categories showed significant and positive effects $(P<.001)$, and there were significant differences between groups $(P=$ $.001)$ : no involvement $(r=.047)$, minimal $(r=.057)$, moderate $(r=.082)$, and high $(r=.094)$.

\section{Discussion}

The main objective of this meta-analysis was to assess the efficacy of intervention programs on the BMI of children and adolescents, as well as explore the possible differences between the school and after-school intervention programs.

The overall effect was of low magnitude $(r=.068)$, although statistically significant $(P<.001)$.

As in previous meta-analysis reviews, ${ }^{23,27}$ the results of this study indicate that there is much work to be done to identify the best practices for preventing the onset of obesity.

In present study the magnitude of the effects produced by both school $(r=.069)$ and after-school based $(r=.065)$ interventions on body composition in children were very similar. Equivalent effect sizes were described by Cook-Cottone et $\mathrm{al}^{23}$ for prevention programs in schools $(r=.05, P<.001)$. From the studies analyzed, only $38 \%$ produced significant effects in preventing weight gain. However, in the study from Stice et al, ${ }^{27}$ the average effect of the interventions was even lower $(r=.04)$.

The low magnitude of results may be due to the great diversity of intervention programs (type of program, duration, type of activities, frequency and intensity of the sessions) applied by the different studies. In addition, it is possible that lack of involvement or attendance on the part of the children, particularly in the sessions of afterschool intervention programs, may have also contributed to the observed results.

However, it was expected that PA intervention programs in school settings would have greater effects than after-school PA interventions programs. The explanation could be that the rules established during school time may lead to the impression that the goals were reached during school and there is no need to maintain the behavior after school. It is possible that the changes in PA levels and eating habits imposed through school interventions may lead to a decrease of PA as well as an increase of caloric intake after school.

The reverse can also happen. Whenever changes are made outside school, the participants can change their behavior during the time they spend in school.

In fact, the effectiveness of an intervention program in a school environment or elsewhere may be influenced by many factors that may be beyond the control of researchers. The Influence of participants' age, parental involvement, the environment/culture and socioeconomic status can impair the effectiveness of the intervention. ${ }^{46}$

The efficacy of the interventions can be optimized if programs consider the specific characteristics of each participant, basing their prescriptions on individual needs.

The age of the participants proved to be a moderator variable, with higher effect size in the sampled programs with participant ages between $15-19$ years $(r=.133)$. Theoretically, older participants are more autonomous and able to exert greater control over their food choices and PA than younger participants. ${ }^{27}$ Teenagers are also known to be less active than children, ${ }^{47}$ thus may have greater potential for change. ${ }^{48}$

Our results follow this hypothesis; however, the effect of the 36 intervention programs that included children up to age 10 was quite similar to the intervention programs that included children with ages between 15-19 years. Cook-Cottone et $\mathrm{al}^{23}$ also found a higher effect in intervention with young children when age is analyzed as a moderator variable.

Parental and community involvement may have a stronger influence on the effectiveness of changes in dietary and PA levels in children than in adolescents. ${ }^{49}$

The analysis of gender as a moderator variable indicated that interventions with mixed groups (girls and boys) produced a greater effect $(r=.110)$ when compared with intervention programs with girls only $(r=.073)$. When the intervention programs were applied to mixed groups but data analysis was performed separately for males and females (male $r=.005$, female $r=.030$ ), the size of the effect was even smaller.

In both types of studies the girls always presented higher effect sizes than boys, which theoretically allows us to say that girls may be more receptive to interventions programs that promotes weight control, ${ }^{27}$ or that the specific characteristics of the implemented programs led to better effects in girls. This brings us to the importance of verifying if altering some of the characteristics of interventions can produce better results in male subjects. Issues related to sexual maturation may also affect these results in a misleading way. ${ }^{50}$ Therefore, in future research, authors should consider the results of sexual maturity classification as covariate to verify if the effect size of intervention programs still favors girls.

The analysis of program duration on the effectiveness of the interventions revealed that, although all programs obtained significant effects, programs with a duration of 1 year were the most effective $(r=.095)$. Unexpectedly, the interventions lasting more than 1 year produced a smaller effect $(r=.086)$. Likewise, the meta-analysis conducted by Cook-Cottone et $\mathrm{al}^{23}$ revealed that programs lasting more than 32 weeks have a lower effect $(r=.05)$ than programs lasting 28-32 weeks $(r=.07)$.

Even though longer interventions increase the possibility of weight loss and facilitate learning skills, they can also become boring for the participants and drop-outs can occur. ${ }^{46,48}$ 
Therefore, it is possible that some specific characteristics inherent to each program may increase the adherence of its participants, as well as its effectiveness in reducing BMI.

The specific characteristics of the intervention may influence effectiveness. The analysis that follows considering the type of intervention program as a moderator variable reflects this.

Programs that combined PA and D were the most effective $(r=.148)$ in reducing BMI; this was consistent with expectations that programs that address the balance between food intake and energy expenditure would prove the most effective.

This occurred in the 16 programs that also included LS $(r=.088)$. Similar results $(r=.082)$ were obtained by interventions that combined LS and D.

From these results we can conclude that, even in the absence of an effective increase in PA levels, intervention aiming to reduce sedentary behaviors and promoting a healthy diet can be a positive influence on BMI reduction.

When the intervention programs included PA, LS, and D simultaneously, the effects, although statistically significant, were of low magnitude $(r=.047)$.

Unpredictably, the programs involving only PA and even those combining PA with LS were not successful in reducing children's BMI. It is possible that the failure of these programs is due to an insufficient amount of PA, or poor adherence by overweight children.

We can also consider other explanations, such as the idea that the unexpected results of the PA programs are not related to the PA itself, but to the selected outcome measure, namely BMI. ${ }^{5}$ BMI may not accurately reflect a child's fat mass loss.

A detailed description of the methodologies used in the measurements, as well as the type of physical activities that were performed, including the intensity and frequency, would allow future meta-analyses to be more consistent.

The frequency of the PA sessions is typically described by the majority of the authors. Most of the programs held $3-5$ sessions a week. This frequency showed a higher effect size $(r=.080)$ than frequencies of 1 to 2 sessions per week $(r=.029)$, or even intervention programs held more than 5 times per week $(r=.077)$. It was expected that an increase of the number of sessions per week would proportionally increase the size of the effects. However, when the interventions were applied 5 days per week, the effect size was small.

Looking specifically at 3 of the studies considered allows us to see that results can conflict. For example, the intervention carried out by Dzewaltowski et al Dzewaltowski, Rosenkranz, Geller, Coleman, Welk, Hastmann, Milliken ${ }^{15}$ with daily PA sessions, organized for at least 30 minutes, produced quite satisfactory results $(r=.59)$. Melnyk et al ${ }^{51}$ obtained exactly the same results $(r=$ .59) with sessions of 20-30 minutes of PA, but with a frequency of 1-2 times week. In the study carried out by Alves et $\mathrm{al}^{52}$ involving recreational activities of moderate energy expenditure (playing ball, running, jumping, dancing) and aerobic sessions, the effect size of reduction in the BMI of 78 children was much more modest $(r=.05)$.

In the current study, the intensity of the PA was not considered, since such parameters were not described by most of the studies analyzed. Lack of information on this variable may bias the interpretation of results, since the effect size of the intervention programs in the BMI of children are exclusively based on the frequency of PA sessions.

The programs considered by our analysis to involve moderate PA frequency may have included more intense PA than the higher frequency programs. It may also be the case that children engage more effectively in the sessions when the intervention allows 1-2 days of rest.

The effect size of intervention programs increases as the level of parental intervention also increases. The programs with high parental involvement (for example, when parents are required to comply with a change of behavior) were the ones which had a significantly stronger effect $(r=.094, P<.001)$.

In interventions that did not include the involvement of parents, the effect size was considerably lower $(r=.047)$ but also statistically significant. Although the results are in line with what would be expected, it should be noted that even though the programs calls for parental involvement, their participation is not always active and assiduous.

\section{Study Limitations}

It should be mentioned that the current study does not represent the available evidence based on the topic of children's obesity prevention, but quantitative estimates the effect size of school and after-school intervention programs, including the correlation between some moderating variables, on the BMIs of children and adolescents. As it was already mentioned, only studies indexed in PubMed databases were considered, putting aside all others studies such as master or $\mathrm{PhD}$ thesis and nonindexed publications which could bias our results.

BMI is an outcome measure commonly used to classify children and young people (normal-weight, overweight and obese) under 18 years old. ${ }^{38}$ However, some authors note that the body changes and interindividual variability inherent to the stage of sexual maturation may interfere with the interpretation of BMI results. ${ }^{40}$ Jamner et $\mathrm{a}^{53}$ suggest the use of classification tables of sexual maturation as a way of controlling for differences in the sexual development of children and adolescents.

Weighing and measuring procedures can also add substantial variability in BMI values. To try to minimize this problem, other outcome measures have been suggested (waist circumference, skinfolds, percentage of fat mass) by McCarthy ${ }^{54}$ as a way of screening for bias caused by the use of BMI alone. However, BMI has been shown to correlate effectively with body fat even in children and adolescents. ${ }^{39}$ 
In the future, reviews should be conducted using several anthropometric measurements and evaluating their impact on the metabolic profile of children. ${ }^{20}$

Another limitation of our study was the difficulty of categorizing the intensity of PA prescribed by each of the intervention programs.

Indeed, it is important that the methodologies used in the interventions be described. In the review carried out by Cook-Cottone et $\mathrm{al}^{23}$ they found low value in activities performed at high intensities $(r=.05, P<.001)$. Further meta-analysis studies are needed to determine the effect size of this variable.

Our study did not examine socioeconomic status, which can also be a moderator variable. The research conducted by Plachta-Danielzik et al ${ }^{55}$ over a period of 4 years has shown that the incidence of obesity decreased only among children from families of high socioeconomic status.

Easy access to healthier food, which can be more expensive in poorer neighborhoods, as well as the ability to pay sports activity fees, can make a difference in the effect of an intervention program in the prevention of obesity in children.

\section{Conclusions}

This systematic review indicated that intervention programs had a positive effect in prevention and in decreasing the obesity in children, although this effect is of low magnitude $(r=.068)$. The programs with older children seem to be more effective compared with those targeted at younger children. Nonetheless, the effect sizes of interventions involving children 10 years of age or younger are very similar to those involving older children. Girls achieved higher effect sizes than boys. The intervention programs with mixed groups (girls and boys) produced a greater effect than the intervention programs with girls only.

After-school programs had a very similar effect to those interventions developed in school settings. The results of the current study also demonstrate that intervention programs of 1 year in length had a greater effect size than those with longer or shorter durations.

According to the present analysis, the intervention programs that best contribute to the prevention of obesity in children use a multifaceted approach including PA, D and parental involvement.

\section{References}

1. Taskforce IO. Childhood obesity. Available from: http:// www.iotf.org/childhoodobesity.asp. 2010.

2. Vandelanotte C, Sugiyama T, Gardiner P, Owen N. Associations of leisure-time internet and computer use with overweight and obesity, physical activity and sedentary behaviors: cross-sectional study. J Med Internet Res. 2009;11(3):e28. PubMed doi:10.2196/jmir.1084

3. Lee HA, Lee WK, Kong KA, et al. The effect of eating behavior on being overweight or obese during preadolescence. J Prev Med Pub Health. 2011;44(5):226233. PubMed doi:10.3961/jpmph.2011.44.5.226

4. Arluk SL, Branch JD, Swain DP, Dowling EA. Childhood obesity's relationship to time spent in sedentary behavior. Mil Med. 2003;168(7):583-586. PubMed

5. McMurray RG, Harrell JS, Bangdiwala SI, Bradley CB, Deng S, Levine A. A school-based intervention can reduce body fat and blood pressure in young adolescents. $J$ Adolesc Health. 2002;31(2):125-132. PubMed doi:10.1016/ S1054-139X(02)00348-8

6. Taylor RW, McAuley KA, Barbezat W, Strong A, Williams SM, Mann JI. APPLE Project: 2-y findings of a communitybased obesity prevention program in primary school age children. Am J Clin Nutr. 2007;86(3):735-742. PubMed

7. Stock S, Miranda C, Evans S, et al. Healthy Buddies: a novel, peer-led health promotion program for the prevention of obesity and eating disorders in children in elementary school. Pediatrics. 2007;120(4):e1059-e1068. PubMed doi:10.1542/peds.2006-3003

8. Angermayr L, Melchart D, Linde K. Multifactorial lifestyle interventions in the primary and secondary prevention of cardiovascular disease and type 2 diabetes mellitus-a systematic review of randomized controlled trials. Ann Behav Med. 2010;40(1):49-64. PubMed doi:10.1007/ s12160-010-9206-4

9. Must A, Strauss RS. Risks and consequences of childhood and adolescent obesity. Int J Obes Relat Metab Disord. 1999;23(Suppl 2):S2-S11. PubMed doi:10.1038/ sj.ijo.0800852

10. Must A, Anderson SE. Effects of obesity on morbidity in children and adolescents. Nutr Clin Care. 2003;6(1):4-12. PubMed

11. Zametkin AJ, Zoon CK, Klein HW, Munson S. Psychiatric aspects of child and adolescent obesity: a review of the past 10 years. J Am Acad Child Adolesc Psychiatry. 2004;43(2):134-150. PubMed doi:10.1097/00004583-200402000-00008

12. Huang SH, Weng KP, Hsieh KS, et al. Effects of a classroom-based weight-control intervention on cardiovascular disease in elementary-school obese children. Acta Paediatr Taiwan. 2007;48(4):201-206. PubMed

13. Barbeau P, Johnson MH, Howe CA, et al. Ten months of exercise improves general and visceral adiposity, bone, and fitness in black girls. Obesity (Silver Spring). 2007;15(8):2077-2085. PubMed doi:10.1038/ oby. 2007.247

14. Burrows T, Warren JM, Collins CE. The impact of a child obesity treatment intervention on parent child-feeding practices. Int J Pediatr Obes. 2010;5(1):43-50. PubMed

15. Dzewaltowski DA, Rosenkranz RR, Geller KS, et al. HOP'N after-school project: an obesity prevention randomized controlled trial. Int J Behav Nutr Phys Act. 2010;7:90. PubMed doi:10.1186/1479-5868-7-90

16. Reilly JJ, Kelly L, Montgomery C, et al. Physical activity to prevent obesity in young children: cluster randomised controlled trial. BMJ. 2006;333(7577):1041. PubMed doi:10.1136/bmj.38979.623773.55

17. Williamson DA, Copeland AL, Anton SD, et al. Wise Mind project: a school-based environmental approach for 
preventing weight gain in children. Obesity (Silver Spring). 2007;15(4):906-917. PubMed doi:10.1038/oby.2007.597

18. Neumark-Sztainer D, Haines J, Robinson-O'Brien R, et al. 'Ready. Set. ACTION!' A theater-based obesity prevention program for children: a feasibility study. Health Educ Res. 2009;24(3):407-420. PubMed doi:10.1093/her/cyn036

19. James J, Thomas P, Cavan D, Kerr D. Preventing childhood obesity by reducing consumption of carbonated drinks: cluster randomised controlled trial. BMJ. 2004;328(7450):1237. PubMed doi:10.1136/ bmj.38077.458438.EE

20. Harris KC, Kuramoto LK, Schulzer M, Retallack JE. Effect of school-based physical activity interventions on body mass index in children: a meta-analysis. CMAJ. 2009;180(7):719-726. PubMed doi:10.1503/cmaj.080966

21. Kropski JA, Keckley PH, Jensen GL. School-based obesity prevention programs: an evidence-based review. Obesity (Silver Spring). 2008;16(5):1009-1018. PubMed doi:10.1038/oby.2008.29

22. Ng C, Anderson K, McQuillen K, Yu BN. School-based obesity and type 2 diabetes prevention programs: a public health perspective. Canadian Journal of Diabetes. 2005;29(3):211-219.

23. Cook-Cottone C, Casey CM, Feeley TH, Baran J. A metaanalytic review of obesity prevention in the schools: 19972008. Psychol Sch. 2009;46(8):695-719. doi:10.1002/ pits.20409

24. Zenzen W, Kridli S. Integrative review of school-based childhood obesity prevention programs. J Pediatr Health Care. 2009;23(4):242-258. PubMed doi:10.1016/j. pedhc.2008.04.008

25. Beets MW, Beighle A, Erwin HE, Huberty JL. After-school program impact on physical activity and fitness: a metaanalysis. Am J Prev Med. 2009;36(6):527-537. PubMed doi:10.1016/j.amepre.2009.01.033

26. Moher D, Liberati A, Tetzlaff J, Altman DG. Preferred reporting items for systematic reviews and meta-analyses: the PRISMA statement. BMJ. 2009;339:b2535. PubMed doi:10.1136/bmj.b2535

27. Stice E, Shaw H, Marti CN. A meta-analytic review of obesity prevention programs for children and adolescents: the skinny on interventions that work. Psychol Bull. 2006;132(5):667-691. PubMed doi:10.1037/0033-2909.132.5.667

28. Barlow SE. Expert committee recommendations regarding the prevention, assessment, and treatment of child and adolescent overweight and obesity: summary report. Pediatrics. 2007;120(Suppl 4):S164-S192. PubMed doi:10.1542/peds.2007-2329C

29. Goran MI, Reynolds K. Interactive multimedia for promoting physical activity (IMPACT) in children. Obes Res. 2005;13(4):762-771. PubMed doi:10.1038/oby.2005.86

30. Liu A, Hu X, Ma G, et al. Evaluation of a classroom-based physical activity promoting programme. Obes. Rev Mar. 2008;9(Suppl 1):130-134.

31. Jiang J, Xia X, Greiner T, Wu G, Lian G, Rosenqvist U. The effects of a 3-year obesity intervention in schoolchildren in Beijing. Child Care Health Dev. 2007;33(5):641-646. PubMed doi:10.1111/j.1365-2214.2007.00738.x
32. Harrison M, Burns CF, McGuinness M, Heslin J, Murphy NM. Influence of a health education intervention on physical activity and screen time in primary school children: 'Switch Off-Get Active'. J Sci Med Sport. 2006;9(5):388394. PubMed doi:10.1016/j.jsams.2006.06.012

33. Story M, Sherwood NE, Himes JH, et al. An after-school obesity prevention program for African-American girls: the Minnesota GEMS pilot study. Ethn Dis. 2003;13(1, Suppl 1):S54-S64. PubMed

34. Annesi JJ, Pierce LL, Bonaparte WA, Smith AE. Preliminary effects of the Youth Fit For Life protocol on body mass index in Mexican American children in YMCA before- and after-school care programs. Hisp Health Care Int. 2009;7:123-129. doi:10.1891/1540-4153.7.3.123

35. Vanhelst J, Mikulovic J, Fardy P, et al. Effects of a multidisciplinary rehabilitation program on pediatric obesity: the CEMHaVi program. Int J Rehabil Res. 2011;34(2):110-4. PubMed

36. Bukara-Radujkovic G, Zdravkovic D. Physical activity as an important determinant in developing childhood obesity. Med Pregl. 2009;62(3-4):107-113. PubMed doi:10.2298/ MPNS0904107B

37. Fulton JE, Wang X, Yore MM, Carlson SA, Galuska DA, Caspersen CJ. Television viewing, computer use, and BMI among U.S. children and adolescents. J Phys Act Health. 2009;6(Suppl 1):S28-S35. PubMed

38. Cole TJ, Bellizzi MC, Flegal KM, Dietz WH. Establishing a standard definition for child overweight and obesity worldwide: international survey. BMJ. 2000;320:12401243. PubMed doi:10.1136/bmj.320.7244.1240

39. Sweeting HN. Measurement and definitions of obesity in childhood and adolescence: a field guide for the uninitiated. Nutr J. 2007;6:32. PubMed doi:10.1186/1475-2891-6-32

40. Gortmaker SL, Peterson K, Wiecha J, et al. Reducing obesity via a school-based interdisciplinary intervention among youth: Planet Health. Arch Pediatr Adolesc Med. 1999;153(4):409-418. PubMed doi:10.1001/ archpedi.153.4.409

41. Cohen J. A power primer. Psychol Bull. 1992;112(1):155159. PubMed doi:10.1037/0033-2909.112.1.155

42. Light R, Pillemar D. Summing up: the science of reviewing research. Cambrid, MA: Harvard University Pressge; 2005.

43. Begg CB, Mazumdar M. Operating characteristics of a rank correlation test for publication bias. Biometrics. 1994;50(4):1088-1101. PubMed doi:10.2307/2533446

44. Cochran W. The combination of estimates from different experiments. Biometrics. 1954;10(1):101-129. doi: $10.2307 / 3001666$

45. Borenstein M, Hedges L, Higgins J, Rothstein H. Comprehensive meta-analysis versão 2.2.048. Englewood, NJ: Biostat; 2008.

46. Graf C, Rost SV, Koch B, et al. Data from the StEP TWO programme showing the effect on blood pressure and different parameters for obesity in overweight and obese primary school children. Cardiol Young. 2005;15(3):291-298. PubMed doi:10.1017/S1047951105000594

47. Riddoch CJ, Bo Andersen L, Wedderkopp N, et al. Physical activity levels and patterns of 9- and 15-yr-old European 
children. Med Sci Sports Exerc. 2004;36(1):86-92. PubMed doi:10.1249/01.MSS.0000106174.43932.92

48. van Sluijs EM, McMinn AM, Griffin SJ. Effectiveness of interventions to promote physical activity in children and adolescents: systematic review of controlled trials. BMJ. 2007;335(7622):703. PubMed doi:10.1136/ bmj.39320.843947.BE

49. Economos CD, Hyatt RR, Goldberg JP, et al. A community intervention reduces BMI z-score in children: Shape Up Somerville first year results. Obesity (Silver Spring). 2007;15(5):1325-1336. PubMed doi:10.1038/ oby. 2007.155

50. Kain J, Uauy R, Albala, Vio F, Cerda R, Leyton B. Schoolbased obesity prevention in Chilean primary school children: methodology and evaluation of a controlled study. Int J Obes Relat Metab Disord. 2004;28(4):483-493. PubMed doi:10.1038/sj.ijo.0802611

51. Melnyk BM, Small L, Morrison-Beedy D, et al. The COPE Healthy Lifestyles TEEN program: feasibility, preliminary efficacy, \& lessons learned from an after school group intervention with overweight adolescents. J Pediatr Health Care. 2007;21(5):315-322. PubMed doi:10.1016/j. pedhc.2007.02.009

52. Alves JG, Gale CR, Souza E, Batty GD. [Effect of physical exercise on bodyweight in overweight children: a randomized controlled trial in a Brazilian slum] Cad Saude Publica. 2008;24(Suppl 2):S353-S359. PubMed doi:10.1590/S0102-311X2008001400020

53. Jamner MS, Spruijt-Metz D, Bassin S, Cooper DM. A controlled evaluation of a school-based intervention to promote physical activity among sedentary adolescent females: project FAB. J Adolesc Health . 2004;34(4):279_ 289. PubMed

54. McCarthy HD. Body fat measurements in children as predictors for the metabolic syndrome: focus on waist circumference. Proc Nutr Soc. 2006;65(4):385-392. PubMed

55. Plachta-Danielzik S, Pust S, Asbeck I, et al. Four-year follow-up of school-based intervention on overweight children: the KOPS study. Obesity (Silver Spring). 2007;15(12):31593169. PubMed doi:10.1038/oby.2007.376 


\section{Appendix}

The following is a full list of references that were included in the final meta-analysis and cited in Table 1 .

Angelopoulos PD, Milionis HJ, Grammatikaki E, Moschonis G, Manios Y. Changes in BMI and blood pressure after a school based intervention: the CHILDREN study. Eur J Public Health. 2009;19(3):319-325.

Bayne-Smith M, Fardy PS, Azzollini A, Magel J, Schmitz KH, Agin D. Improvements in heart health behaviors and reduction in coronary artery disease risk factors in urban teenaged girls through a school-based intervention: the PATH program. Am J Public Health. 2004;94(9):1538-1543.

Caballero B, Clay T, Davis SM, et al. Pathways: a school-based, randomized controlled trial for the prevention of obesity in American Indian schoolchildren. Am J Clin Nutr. 2003;78(5):1030-1038.

Carrel AL, Clark RR, Peterson SE, Nemeth BA, Sullivan J, Allen DB. Improvement of fitness, body composition, and insulin sensitivity in overweight children in a school-based exercise program: a randomized, controlled study. Arch Pediatr Adolesc Med. 2005;159(10):963-968.

Damon S, Dietrich S, Widhalm K. PRESTO-Prevention Study of Obesity: a project to prevent obesity during childhood and adolescence. Acta Paediatr Suppl. 2005;94(448):47-48.

Edwards B. Childhood obesity: a school-based approach to increase nutritional knowledge and activity levels. Nurs Clin North Am. 2005;40(4):661-669, viii-ix.

Eliakim A, Nemet D, Balakirski Y, Epstein Y. The effects of nutritional-physical activity school-based intervention on fatness and fitness in preschool children. J Pediatr Endocrinol Metab. 2007;20(6):711-718.

Farias ES, Paula F, Carvalho WR, Goncalves EM, Baldin AD, Guerra-Junior G. Influence of programmed physical activity on body composition among adolescent students. J Pediatr (Rio J). 2009;85(1):28-34.

Foster GD, Sherman S, Borradaile KE, et al. A policy-based school intervention to prevent overweight and obesity. Pediatrics. 2008;121(4):e794-802.

Goldfield GS, Mallory R, Parker T, et al. Effects of open-loop feedback on physical activity and television viewing in overweight and obese children: a randomized, controlled trial. Pediatrics. 2006;118(1):e157-166.

Kafatos I, Manios Y, Moschandreas J, Kafatos A. Health and nutrition education program in primary schools of Crete: changes in blood pressure over 10 years. Eur J Clin Nutr. 2007;61(7):837-845.

Kipping RR, Payne C, Lawlor DA. Randomized controlled trial adapting US school obesity prevention to England. Arch Dis Child. 2008;93(6):469-473.

Lazaar N, Aucouturier J, Ratel S, Rance M, Meyer M, Duche P. Effect of physical activity intervention on body composition in young children: influence of body mass index status and gender. Acta Paediatr. 2007;96(9):1315-1320.

Lohman T, Thompson J, Going S, et al. Indices of changes in adiposity in American Indian children. Prev Med. 2003;37(6 Pt 2):S91-96.

Manios Y, Moschandreas J, Hatzis C, Kafatos A. Health and nutrition education in primary schools of Crete: changes in chronic disease risk factors following a 6-year intervention program. Br J Nutr. 2002;88(3):315-324.

Martinez Vizcaino V, Salcedo Aguilar F, Franquelo Gutierrez R, et al. Assessment of an after-school physical activity program to prevent obesity among 9- to 10-year-old children: a cluster randomized trial. Int J Obes (Lond). 2008;32(1):12-22.

Neumark-Sztainer D, Story M, Hannan PJ, Rex J. New Moves: a school-based obesity prevention program for adolescent girls. Prev Med. 2003;37(1):41-51.

Pangrazi RP, Beighle A, Vehige T, Vack C. Impact of Promoting Lifestyle Activity for Youth (PLAY) on children's physical activity. J Sch Health. 2003;73(8):317-321.

Perman JA, Young TL, Stines E, Hamon J, Turner LM, Rowe MG. A community-driven obesity prevention and intervention in an elementary school. J Ky Med Assoc. 2008;106(3):104-108.

Robbins LB, Gretebeck KA, Kazanis AS, Pender NJ. Girls on the move program to increase physical activity participation. Nurs Res. 2006;55(3):206-216.

Rosenbaum M, Nonas C, Weil R, et al. School-based intervention acutely improves insulin sensitivity and decreases inflammatory markers and body fatness in junior high school students. J Clin Endocrinol Metab. 2007;92(2):504-508.

Sahota P, Rudolf MC, Dixey R, Hill AJ, Barth JH, Cade J. Evaluation of implementation and effect of primary school based intervention to reduce risk factors for obesity. $B M J$. 2001;323(7320):1027-1029.

Salmon J, Ball K, Hume C, Booth M, Crawford D. Outcomes of a group-randomized trial to prevent excess weight gain, reduce screen behaviors and promote physical activity in 10-year-old children: switch-play. Int J Obes (Lond). 2008;32(4):601-612.

Schofield L, Mummery WK, Schofield G. Effects of a controlled pedometer-intervention trial for low-active adolescent girls. Med Sci Sports Exerc. 2005;37(8):1414-1420.

Singh AS, Chin APMJ, Brug J, van Mechelen W. Short-term effects of school-based weight gain prevention among adolescents. Arch Pediatr Adolesc Med. 2007;161(6):565-571.

Skybo TA, Ryan-Wenger N. A school-based intervention to teach third grade children about the prevention of heart disease. Pediatr Nurs. 2002;28(3):223-229, 235.

Spiegel SA, Foulk D. Reducing overweight through a multidisciplinary school-based intervention. Obesity (Silver Spring). 2006;14(1):88-96.

Weintraub DL, Tirumalai EC, Haydel KF, Fujimoto M, Fulton JE, Robinson TN. Team sports for overweight children: the Stanford Sports to Prevent Obesity Randomized Trial (SPORT). Arch Pediatr Adolesc Med. 2008;162(3):232-237.

Yin Z, Gutin B, Johnson MH, et al. An environmental approach to obesity prevention in children: Medical College of Georgia FitKid Project year 1 results. Obes Res. 2005;13(12):2153-2161.

Yin Z, Moore JB, Johnson MH, et al. The Medical College of Georgia Fitkid project: the relations between program attendance and changes in outcomes in year 1. Int J Obes (Lond). 2005;29(Suppl 2):S40-45. 